\title{
PENGEMBANGAN SISTEM KONTROL KIPAS ANGIN DAN LAMPU OTOMATIS BERBASIS SAKLAR SUARA MENGGUNAKAN ARDUINO UNO
}

\author{
Pensi Asmaleni , Dedy Hamdani, Indra Sakti
}

Program Studi Pendidikan Fisika, Fakultas Keguruan dan Ilmu Pendidikan, Universitas Bengkulu Jl. W.R Supratman Kandang Limun, Bengkulu

E-mail*: fensi.asmaleni8@gmail.com

Diterima 8 Agustus 2019

Direvisi 9 April $2020 \quad$ Disetujui 24 April 2020

Dipublikasikan 30 April 2020

https://doi.org/10.33369/jkf.3.1.59-66

\begin{abstract}
ABSTRAK
Penelitian bertujuan untuk (1) menghasilkan rancangan sistem kontrol kipas angin dan lampu otomatis berbasis saklar suara menggunakan Arduino Uno (2) dan menghasilkan alat sistem kontrol kipas angin dan lampu otomatis berbasis saklar suara menggunakan Arduino Uno. Metode penelitian yang digunakan adalah Research and Development. Tahap pengembangan dalam penelitian ini meliputi perancangan, produksi dan evaluasi. Sistem kontrol kipas angin dan lampu otomatis berbasis saklar suara menggunakan Arduino Uno terdiri dari komponen-komponen elektronika seperti Bluetooth HC-05 sebagai koneksi antara smartphone android dengan Arduino Uno, relay sebagai pemutus arus listrik dan Arduino Uno sebagai sistem kontrol dari semua rangkaian. Jarak maksimum jangkauan Bluetooth HC-05 adalah 17 meter tanpa penghalang dan 7 meter dengan penghalang. Adapun hasil validasi isi dan teknis dalam penelitian ini menunjukan bahwa sistem kontrol kipas angin dan lampu otomatis berbasis saklar suara menggunakan Arduino Uno memperoleh persentase sebesar 82,5\% sehingga dikategorikan baik. Berdasarkan data yang diperoleh dapat disimpulkan bahwa sistem kontrol kipas angin dan lampu otomatis berbasis saklar suara menggunakan Arduino Uno layak untuk digunakan sebagai pengontrol lampu berbasis suara.
\end{abstract}

kata kunci: Bluetooth HC-05, relay empat channel, saklar suara, arduino uno.

\section{ABSTRACT}

This study aims to (1) produce a draft control system fan and lamp-based automatic voice switch using the Arduino Uno (2) and generate tool control system fan and lamp-based automatic voice switch using the Arduino Uno. The method was used the Research and Development. The development stage in this research included the design, production and evaluation. The control system and automatic headlights fan-based voice switch using the Arduino Uno consists of electronic components such as HC-05 Bluetooth as the connection between android smartphone with the Arduino Uno, relay as the electric circuit breaker and Arduino Uno as the control systems of all the series. The maximum distance of HC-05 Bluetooth range of 17 meters without obstructions and 7 meters to the barrier. As for the contents and technical validation results from the studied show that the control system fan and automatic light switchbased voice using Arduino Uno obtained a percentage of $82.5 \%$ and good category. Based on the data obtained can be concluded that the control system and automatic headlights fan-based voice switch using the Arduino Uno was eligible to be used as a voice-based lighting controller.

Keywords: Bluetooth HC-05, four-channel relay, voice switch, Arduino Uno.

\section{Pendahuluan}

Lampu merupakan suatu penemuan yang sangat penting bagi manusia karena sebelum adanya lampu, kita masih menggunakan lilin sebagai penerangan ketika malam hari. Namun, masa hidup lilin sangat pendek sehingga manusia mulai mencari sumber penerangan baru. Ketika listrik ditemukan, manusia mulai memanfaatkan listrik untuk penerangan di malam hari dengan media berupa lampu. Lampu adalah sebuah peranti yang memproduksi cahaya. Lampu pertama yang diproduksi adalah lampu pijar. Lampu pijar adalah sumber cahaya buatan yang dihasilkan melalui penyaluran arus listrik melalui filamen yang kemudian memanas dan menghasilkan cahaya [1]. 
Dalam kehidupan sehari-hari, orang sering lupa mematikan lampu atau peralatan eletronik lainnya yang sudah tidak terpakai. Kondisi ini menyebabkan energi listrik terus terpakai dan menyebabkan biaya pemakaian listrik menjadi lebih tinggi. Cara penghematan energi dapat dilakukan dengan melakukan kontrol terhadap alat elektronik agar dapat meminimalisir penggunaan energi listrik di luar kebutuhan. Alasan inilah perlu dirancang sebuah sistem kontrol otomatis untuk perangkat elektronik untuk penghematan energi listrik [2]. Oleh karena itu, dibutuhkan suatu peralatan yang bisa mengontrol peralatan elektronik agar dapat meminimalisir pemakaian energi listrik secara hemat dan tepat.

Teknologi ponsel terus mengalami perkembangan. Saat ini telah dikembangkan ponsel berbasis Android atau yang dikenal sebagai ponsel pintar (Smartphone). Android adalah sistem operasi didalam ponsel yang bersifat open source sehingga dapat memperluas fungsionalitasnya ke batas-batas maksimal. Dengan sistem distribusi open source yang digunakan, memungkinkan para pengembang untuk menciptakan beragam aplikasi menarik yang dapat dinikmati oleh para penggunanya seperti game, chatting, dan aplikasi lain seperti komunikasi jarak jauh menggunakan Arduino. Arduino ialah perangkat keras (hardware) sekaligus perangkat lunak (software) yang sering digunakan dalam pembuatan prototipe suatu rangkaian elektronika yang berbasis mikrokontroler [3]. Salah satu aplikasi dalam smartphone yang dapat dihubungkan dengan Arduino adalah pengontrol peralatan rumah, seperti pengontrol kipas angin dan lampu di dalam rumah.

Pada penelitian sebelumnya, telah dibuat sistem pengontrol lampu secara otomatis. Perancangan prototype sistem kendali lampu dilakukan dengan menggunakan handphone android berbasis Arduino. Dalam penelitian ini, digunakan tombol on/off pada handphone sebagai saklar lampu dan menggunakan aplikasi app inventor. Agar dapat menghubungkan aplikasi app inventor dengan sistem mikrokontroler dibutuhkan Modul Bluetooth HC-05. Jarak jangkauan antara pengguna dengan sistem mikrokontroler adalah $12 \mathrm{~m}$ [4]. Pada penelitian lain juga telah dibuat aplikasi Android untuk pengendali lampu rumah berbasis mikrokontroler Atmega328. Hasil penelitian ini dapat mengendalikan lampu dengan jarak maksimal 13 meter tanpa penghalang dan 10 meter dengan penghalang [5].

Selain itu, penelitian menggunakan saklar suara telah dilakukan yakni membuat sistem lampu dengan sensor gerak, sensor suhu, dan sensor suara berbasis mikrokontroler. Penelitian ini dilakukan di dalam WC mall dengan mengguanakan sensor ky-038 sebagai sensor suara. Sensor ky038 yang aktif akan mendeteksi suara yang dihasilkan seseorang di dalam WC. Hasil yang diperoleh untuk sensor suara ky-038 yang digunakan masih kurang bisa bekerja dengan baik [6]. Penelitian lain yang menggunakan aplikasi app Inventor dengan pengendalian menggunakan perintah suara, namun hanya bisa dilakukan secara online [7]. Pada aplikasi app Inventor, pengontrolan menggunakan saklar suara memerlukan akses internet. Pembacaan suara pada aplikasi ini menggunakan Google Speech. Google Speech ini berfungsi untuk pembacaan suara yang diucapkan.

Faktanya tidak semua orang memiliki akses internet. Saat-saat tertentu juga bisa terjadi gangguan pada internet sehingga lingkungan yang kurang terakses internet akan sulit menggunakan aplikasi ini. Oleh karena itu, dibutuhkan aplikasi yang bisa meminimalisir kendala tersebut yaitu dengan menggunakan aplikasi yang bisa digunakan secara Offline. Aplikasi tersebut dapat dikembangkan sehingga mampu mengontrol lebih dari satu peralatan elektronik menggunakan perintah suara pada smartphone.

Berdasarkan uraian tersebut dibutuhkan penelitian tentang sistem kontrol kipas angin dan lampu otomatis berbasis saklar suara menggunakan Arduino Uno. Tujuan dari penelitian ini adalah untuk merancang dan membuat alat tentang sistem kontrol kipas angin dan lampu otomatis berbasis saklar suara menggunakan Arduino Uno.

\section{Metodologi Penelitian}

Jenis penelitian ini adalah penelitian dan pengembangan (Research and Development). Metode penelitian dan pengembangan atau dalam bahasa inggrisnya Research and Development 
adalah metode penelitian yang digunakan untuk menghasilkan produk baru, menguji keefektifan produk yang telah ada, serta mengembangkan dan menciptakan produk baru [8].

Prosedur penelitian dan pengembangan tersebut adalah sebagai berikut:

PLANNING $\rightarrow$ PRODUCTION

\subsection{Perancangan Diagram Blog Sistem}

\section{Gambar 1. Langkah R\&D}

Perancangan perangkat keras (hardware) secara umum dapat digambarkan pada diagram blok pada Gambar 2 berikut.

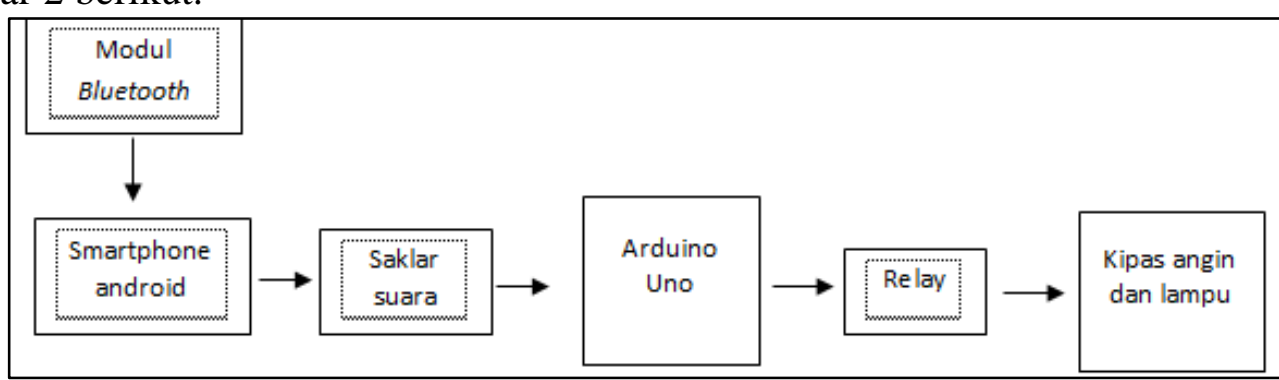

Gambar 2. Diagram Blok Rancangan Sistem Kontrol Kipas Angin dan Lampu Otomatis Berbasis Saklar Suara Menggunakan Arduino Uno

\subsection{Perancangan Perangkat Lunak (software)}

Perancangan perangkat lunak terfokus pada pemprograman Arduino. Perancangan perangkat lunak pada alat ini dibangun menggunakan bahasa $C$. Keseluruhan maupun perangkat lunak untuk mengakses bagian-bagian dari sistem diatur didalam Arduino Uno R3. Adapun flowchart dari perangkat lunak pada set eksperimen ini ditunjukkan pada gambar 3 sebagai berikut:

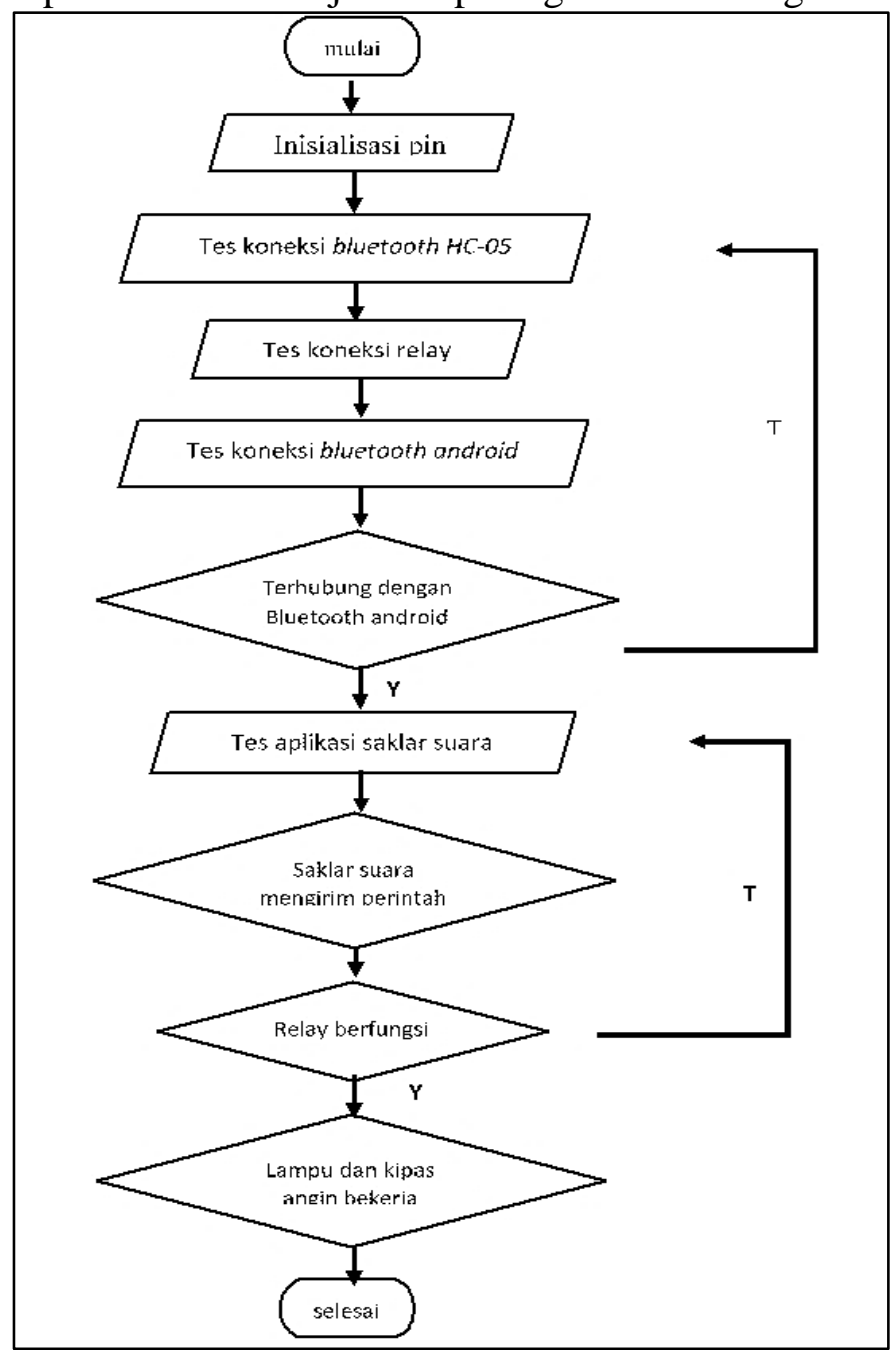

Gambar 3. Flowchart Sistem Pengontrol 


\subsection{Design rangkaian keseluruhan}

Pada perancangan ini dibuat rancangan rangkaian tiap komponen utama yang nantinya dihubungkan dengan komponen pendukung lainnya agar produk yang dihasilkan dapat berjalan sesuai dengan yang diharapkan. Setelah dilakukan perancangan untuk tiap-tiap komponen, maka selanjutnya dilakukan penggabungan semua komponen yang digunakan menjadi suatu sistem yang dapat mengontrol kipas angin dan lampu secara otomatis menggunakan perintah suara. Adapun rangkaian keseluruhan komponen yang digunakan dapat dilihat pada gambar 4 .

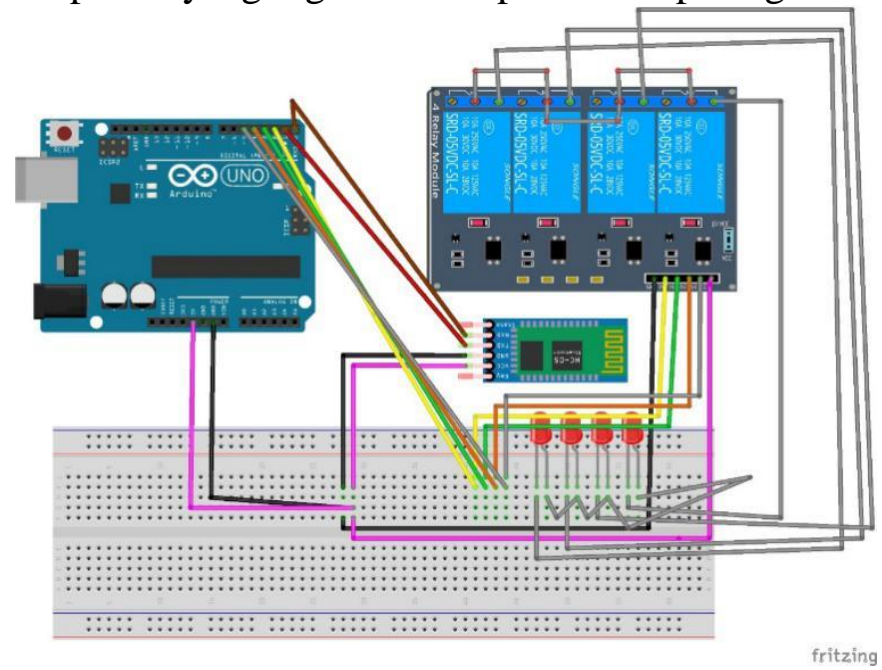

Gambar 4. Rangkaian Keseluruhan

Rangkaian pada gambar 4 adalah rangkaian keseluruhan dari penggabuangan komponen Arduino Uno, relay empat channel dan modul Bluetooth yang dirangkai diatas papan breadboard dan terhubung oleh kabel jumper.

Instrument penelitian ini berupa angket yang berisi pernyataan mengenai alat kontrol yang akan di validasi. Untuk penelitian dan pengembangan ini, skala Likert yang digunakan ialah skala yang berjumlah 5, seperti di bawah ini: (1) Sangat Baik (SB): 5 (2) Baik (B): 4 (3) Cukup Baik (CB): 3 (4) Kurang Baik (KB): 2 (5) Sangat Tidak Baik (STB): 1. Ketika data kuisioner telah terkumpul, kemudian dilakukan pengolahan data, disajikan dalam bentuk table dan dianalisis.

Pada tabel 1 terdapat kisi-kisi angket tim ahli sistem kontrol kipas angin dan lampu otomatis berbasis saklar suara.

Tabel 1. Kisi-kisi Angket Tim Ahli

\begin{tabular}{cccc}
\hline Variabel & Aspek & Nomor Item & Jumlah Item \\
\hline KomponenKelayakan & Kesesuaian & $3,4,12,14$ & 4 \\
Isi dan Komponen & Kemudahan & $5,6,7,9,10$ & 5 \\
Teknis & Kemenarikan & $9,11,13$ & 3 \\
& Kemanfaatan & $1,8,15,16,17,18,19,20$ & 8 \\
\hline
\end{tabular}

Untuk mengetahui keadaan baik atau belumnya sistem kontrol kipas angin dan lampu otomatis berbasis saklar suara yang dibuat, maka terlebih dahulu akan mencari nilai rata-rata (mean) dan nilai frekuensi relatif dari angket tersebut. Nilai rata-rata dihitung dengan menggunakan persamaan:

$$
M x=\frac{\sum x}{N}
$$

dengan Mx adalah mean (rata-rata), $\sum \mathrm{x}$ adalah jumlah seluruh skor, dan $\mathrm{N}$ adalah banyaknya skor [9].

Nilai frekuensi relatif dihitung dengan menggunakan persamaan:

$$
P=\frac{f}{N} .100 \%
$$

dengan $\mathrm{P}$ adalah angka presentase, $\mathrm{f}$ adalah frekuensi yang sedang dicari presentasenya, dan $\mathrm{N}$ adalah jumlah frekuensi. Skor dikategorikan dalam 2 kategori yaitu skor maksimum $(X \max )$ dan 
skor minimum ( $X$ min), serta dicari juga range dari nilai tersebut. Skor minimum adalah jumlah butir angket dikali skor terkecil $(20 \mathrm{x} 1=20)$. Skor maksimum adalah jumlah butir angket dikali skor terbesar (20x5=100). Jangkauan atau Range adalah skor maksimum dikurang skor minimum (100$20=80$ ) sehingga diperoleh

$$
\text { interval kriteria }=\frac{\text { range }}{\text { jumlah } \text { kriteria penelitian }}=\frac{80}{5}=16
$$

Jadi, kisaran untuk penilaian tim ahli adalah (1) Sangat Baik (SB): 84-100, (2) Baik (B): 68-83, (3) Cukup Baik (CB): 52-57, (4) Kurang Baik (KB): 36-51, dan (5) Sangat Tidak Baik (STB): 20-35. Selanjutnya, katagori kelayakan dikategorikan dengan skala sebagai berikut:

Tabel 2. Kategori Kelayakan Berdasarkan Rating Scale

\begin{tabular}{ccc}
\hline No & Skor dalam Persen (\%) & Kategori \\
\hline 1 & $0 \%-35 \%$ & Sangat Tidak Baik \\
2 & $>35 \%-51 \%$ & Kurang Baik \\
3 & $>51 \%-67 \%$ & Cukup Baik \\
4 & $>67 \%-83 \%$ & Baik \\
5 & $>83 \%-100 \%$ & Sangat Baik \\
\hline
\end{tabular}

Setelah semuanya selesai, maka dapat ditentukan letak tanggapan tim ahli secara keseluruhan

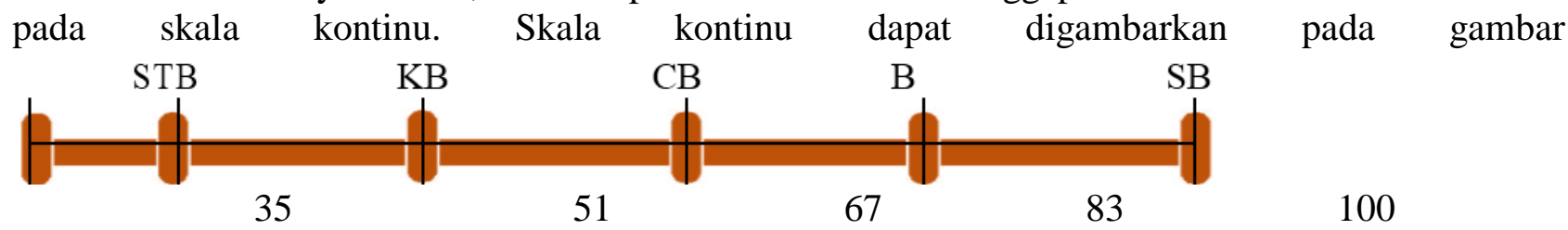

Gambar 5. Letak Tanggapan Tim Ahli seperti berikut:

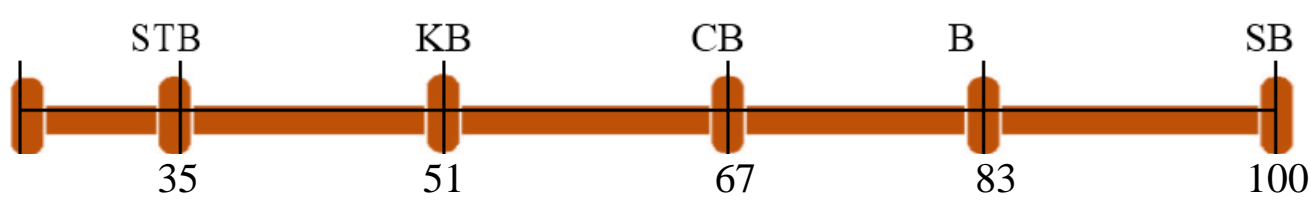

Gambar 5. Letak Tanggapan Tim Ahli [8]

\section{Hasil dan pembahasan}

Pada penelitian ini sudah dibuat sistem kontrol kipas angin dan lampu otomatis berbasis saklar suara menggunakan Arduino Uno sesuai dengan rancangan. Saklar suara bisa diakses apabila Bluetooth HC-05 sudah terhubung dengan Smartphone Android. Perintah suara yang dilakukan pada aplikasi akan berkerja bila sesuai dengan kode program yang sudah dibuat. Rangkaian kipas angin dan lampu dibuat secara paralel diatas papan triplek, kemudian dihubungkan dengan rangkaian relay, Bluetooth $\mathrm{HC}-05$, dan Arduino Uno. Apabila pengguna melakukan perintah suara untuk mengontrol lampu atau kipas angin maka sistem pengontrol akan melakukan kontrol sesuai dengan yang diberikan oleh pengguna. Gambar rangkaian keseluruhan bisa dilihat pada gambar 6

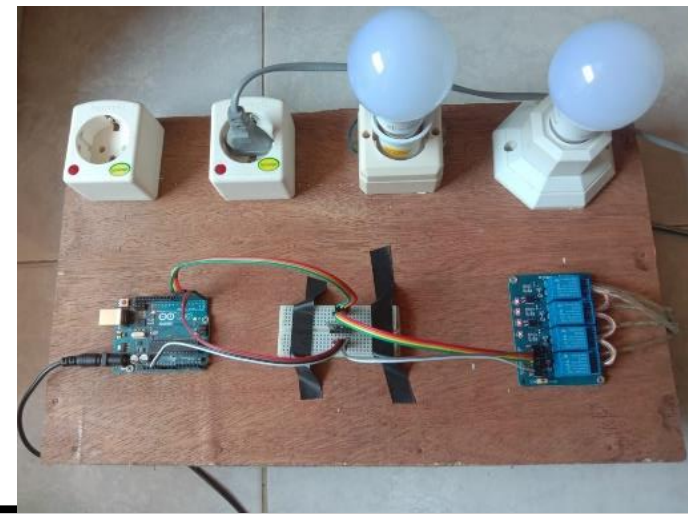




\section{Gambar 6. Rangkaian Keseluruhan}

Pengujian sistem kontrol kipas angin dan lampu otomatis berbasis saklar suara menggunakan Arduino uno dilakukan bebarapa tahap yaitu oleh validasi tim ahli, pengujian Bluetooth, pengujian relay dan pengujian saklar suara. Tingkat presentase kelayakan sistem kontrol kipas angin dan lampu otomatis berbasis saklar suara menggunakan Arduino Uno dapat dilihat dengan menggunakan angket. Sistem ini dinilai oleh dua orang ahli yang disajikan pada tabel 3.

Tabel 3. Validasi Design dan Alat Sistem Kontrol Kipas Angin dan Lampu Otomatis Berbasis Saklar Suara Menggunakan Arduino Uno oleh Tim Ahli

\begin{tabular}{ccc} 
Validator & Persentase $(\boldsymbol{\%})$ & Kategori \\
\hline Validator 1 & 83 & Baik \\
Validator 2 & 82 & Baik \\
Rata-rata & 82,5 & Baik
\end{tabular}

Dari data di atas dapat dilihat bahwa tim ahli pertama menyatakan design rancangan serta alat sistem kontrol kipas angin dan lampu berbasis saklar suara dalam kategori baik dengan persentase $83 \%$. Sama halnya dengan tim ahli kedua yang menyatakan bahwa design rancangan serta alat sistem kontrol kipas angin dan lampu otomatis berbasis saklar suara sangat baik dengan persentase $82 \%$. Berdasarkan data hasil uji validasi tersebut, maka dapat disimpulkan bahwa validasi design dan alat sistem kontrol kipas angin dan lampu berbasis saklar suara adalah baik.

Penilaian uji kelayakan sistem kontrol kipas angin dan lampu otomais berbasis saklar suara ini ditinjau dari dua aspek yaitu aspek isi dan aspek teknis. Tingkat presentase kelayakan sistem Kontrol kipas angin dan lampu otomatis berbasis saklar suara menurut tim ahli disajikan dalam table 4.

Tabel 4. Data Penilaian Alat oleh Tim Ahli Ditinjau dari Aspek

\begin{tabular}{cccccc}
\hline No & Aspek & Jumlah & Max & Persentase \% & Kategori \\
\hline 1 & Isi & 63 & 80 & $78,75 \%$ & Baik \\
2 & Teknis & 102 & 120 & $85 \%$ & Sangat baik \\
\hline
\end{tabular}

Dari penilaian sistem kontrol kipas angin dan lampu otomatis berbasis saklar suara diatas dapat diketahui bahwa dari aspek isi memperoleh 78,75 \% berada dalam kategori baik. Dan dari aspek teknis juga memperoleh $85 \%$ berada dalam kategori sangat baik.

Jarak batas maksimum koneksi Bluetooth HC-05 dengan handphone android dapat dilihat pada tabel 5 berikut.

Tabel 5. Hasil Pengujian Bluetooth HC-05 dengan Android

\begin{tabular}{cccccc}
\hline $\begin{array}{c}\text { Jarak } \\
\text { (Meter) }\end{array}$ & $\begin{array}{c}\text { Tanpa } \\
\text { Penghalang }\end{array}$ & $\begin{array}{c}\text { Dengan } \\
\text { Penghalang }\end{array}$ & $\begin{array}{c}\text { Jarak } \\
\text { (Meter) }\end{array}$ & $\begin{array}{c}\text { Tanpa } \\
\text { Penghalang }\end{array}$ & $\begin{array}{c}\text { Dengan } \\
\text { Penghalang }\end{array}$ \\
\hline 1 & Terhubung & Terhubung & 10 & Terhubung & Tidak Terhubung \\
2 & Terhubung & Terhubung & 11 & Terhubung & Tidak Terhubung \\
3 & Terhubung & Terhubung & 12 & Terhubung & Tidak Terhubung \\
4 & Terhubung & Terhubung & 13 & Terhubung & Tidak Terhubung \\
5 & Terhubung & Terhubung & 14 & Terhubung & Tidak Terhubung \\
6 & Terhubung & Terhubung & 15 & Terhubung & Tidak Terhubung \\
7 & Terhubung & Terhubung & 16 & Terhubung & Tidak Terhubung \\
8 & Terhubung & Tidak Terhubung & 17 & Terhubung & Tidak Terhubung \\
9 & Terhubung & Tidak Terhubung & 18 & Tidak Terhubung & Tidak Terhubung \\
\hline
\end{tabular}


Berdasarkan tabel tersebut jarak maksimum konektivitas modul Bluetooth HC-05 dengan smartphone android dengan adanya penghalang dan dengan tidak ada penghalang berbeda. Saat Bluetooth diletakkan di area terbuka jarak maksimum jangkauan Bluetooth adalah 17 meter. Sedangkan untuk pengujian modul Bluetooth HC-05 menggunakan penghalang jarak maksimum konektivitasnya adalah 7 meter. Pengujian menggunakan penghalang menempatkan Modul Bluetooth di dalam ruangan sedangkan Smartphone Android diletakkan di ruangan yg berbeda yang dipisahkan oleh dinding.

Pengujian Saklar suara dilakukan di LAB Fisika FKIP Universitas Bengkulu. Pengujian saklar suara ini dilakukan dengan menguji aplikasi saklar menggunakan penghalang dan dengan tidak menggunakan penghalang. Pengujian saklar suara ini sama dengan pengujian sistem secara keseluruhan yang bertujuan untuk mengetahui batas fungsi maksimum sistem dari jarak tertentu. Sistem kontrol kipas angin dan lampu otomatis dikatakan berfungsi jika sistem mampu bekerja sesuai dengan perintah yang dilakukan oleh pengguna. Pada pengujian relay empat channel yang dipasang pada kipas angin dan lampu, data pengujian dapat dilihat pada tabel 6 .

Tabel 6. Hasil Pengujian Relay Empat Channel pada Lampu dan Kipas Angin

Relay Saklar Keterangan

\begin{tabular}{lll}
\hline Channel ke 1 & Lampu taman & Berfungsi \\
Channel ke 2 & Kipas angin & Berfungsi \\
Channel ke 3 & Lampu teras & Berfungsi \\
Channel ke 4 & Pendingin & Berfungsi \\
\hline
\end{tabular}

Dari tabel tersebut relay berfungsi dengan baik memutus aliran listrik pada saklar lampu taman, lampu teras, kipas angin dan pendingin. Channel 1 untuk saklar lampu taman, channel 2 untuk saklar kipas angin, channel 3 untuk lampu teras dan channel 4 untuk pendingin. Peralatan elektronik yang digunakan bisa diubah sesuai kebutuhan.

Pengujian Saklar suara dilakukan di LAB Fisika FKIP Universitas Bengkulu. Pengujian saklar suara ini dilakukan dengan menguji aplikasi saklar menggunakan penghalang dan dengan tidak menggunakan penghalang. Pengujian saklar suara ini sama dengan pengujian sistem secara keseluruhan yang bertujuan untuk mengetahui batas fungsi maksimum sistem dari jarak tertentu. Sistem kontrol kipas angin dan lampu otomatis dikatakan berfungsi jika sistem mampu bekerja sesuai dengan perintah yang dilakukan oleh pengguna.

Pada pengujian saklar suara tanpa penghalang, diberikan jarak $1 \mathrm{~m}, 3 \mathrm{~m}$, sampai $17 \mathrm{~m}$ sesuai dengan batas maksimum konektivitas modul Bluetooth $\mathrm{HC}-05$. Sedangkan pada pengujian saklar suara dengan penghalang, batas maksimum pengujian Bluetooth dengan penghalang adalah 7 meter. Pengujian saklar suara dengan penghalang diuji dengan jarak angka ganjil yaitu dari $1 \mathrm{~m}, 3 \mathrm{~m}, 5 \mathrm{~m}$ sampai $7 \mathrm{~m}$ sesuai dengan batas maksimum konektivitas modul Bluetooth HC-05 dengan penghalang.

Hasil penelitian tersebut sejalan dengan penelitian lain, yakni "Aplikasi android pengendali lampu rumah berbasis mikrokontroler atmega328" yang menggunakan media penghubung Bluetooth menyatakan bahwa jarak yang dapat dijangkau maksimal 13meter tanpa penghalang dan 10meter dengan penghalang [5]. Namun, jika menggunakan Arduino Uno R3 dan smartphone, hasil penelitian menunjukkan Bluetooth smartphone dapat terhubung dengan system pengontrol lebih jauh dari hasil penelitian sebelumnya [10].

\section{Kesimpulan dan Saran}

Setelah dilakukan pembuatan sistem kontrol kipas angin dan lampu otomatis berbasis saklar suara menggunakan Arduino uno kemudian melakukan pengujian alat, maka dapat diambil kesimpulan bahwa Dalam merancang dan membuat sistem kontrol kipas angin dan lampu otomatis berbasis saklar suara menggunakan beberapa alat dan bahan yaitu: Arduino Uno R3 sebagai mikrokontroler, Bluetooth HC-05 sebagai alat komunikasi antara smartphone dengan sistem pengontrol dan relay sebagai saklar lampu dan kipas angin, smartphone android, kabel jumper, 
kabel listrik, fitting lampu, stop kontak, laptop, dan adaptor dan papan PCB. Sistem kontrol kipas angin dan lampu otomatis dibuat dengan merangkai seluruh komponen alat dengan kabel jumper sebagai penghubung antar komponen. Untuk ruang lingkup penggunaan yang lebih luas, pengembangan penelitian selanjutnya disarankan menggunakan aplikasi yang bisa digunakan dengan dua kondisi offline dan online sehingga jarak yang digunakan menjadi tidak terbatas dan bisa digunakan sekalipun pada wilayah yang tidak terjangkau akses internet.

\section{UCAPAN TERIMA KASIH}

Penulis mengucapkan terima kasih kepada dosen dan validator yang telah menjadi bagian dari penelitian dan pihak yang telah membantu.

\section{DAFTAR PUSTAKA}

[1] Pardede, A. M. H., Novriyenni, dan Efendi, S., 2017, Implementasi Pengendalian Lampu Otomatis Berbasis Arduino Menggunakan Metode Fuzzy Logic, Techsi, No. 2, Vol. 9, hal. $164-177$.

[2] Alisman dan Wildian, 2018, Rancang Bangun Sistem Kontrol Gorden, Lampu, dan Kipas Angin Berbasis Arduino Uno R3, Jurnal Fisika Unand, No. 3, vol. 7, hal. 279-285.

[3] Kadir, A., 2016, Pengantar Arduino, PT Elex Media Kamputindo, Jakarta.

[4] Fatoni, A., dan Rendra, D. B., 2014, Perancangan Prototype Sistem Kendali Lampu Menggunakan Handphone Android Berbasis Arduino, PROSISKO, Vol. 1, hal. 23-29.

[5] Giyartono, A. dan Kresnha, P. E., 2015, Aplikasi Android Pengendali Lampu Rumah Berbasis Mikrokontroler Atmega328, Seminar Nasional Sains dan Teknologi, Universitas Muhammadiyah Jakarta, hal. 1-9.

[6] Lukman, M. P., Junaedy, dan Rieuwpassa, Y. F. Y., 2018, Sistem Lampu Otomatis dengan Sensor Gerak, Sensor Suhu dan Sensor Suara Berbasis Mikrokontroler, Jurnal Resistor, No. 2, Vol. 1, hal. 100-108.

[7] Andyka, D., dan Anwar, M. C., 2017, Rancang Bangun Aplikasi Android Pengendalian Smarthome Menggunakan Perintah Suara, Seminar Nasional Humaniora \& Aplikasi Teknologi Informasi (SEHATI), hal. 48-51.

[8] Sugiyono, 2017, Metode Penelitian dan Pengembangan (Research and Development), Alfabeta, Bandung.

[9] Widiyanto, M. A., 2013, Statistika Terapan, PT Elex Media Komputindo, Jakarta.

[10] Girsang Z. dan Ritonga, W., 2019, Rancang Bangun System Pengontrol Lampu Otomatis Berbasis Arduino Uno R3 dan Smartphone, Jurnal Einstein, No. 1, Vol. 7, hal. 32-39. 